\title{
AMELIORATION OF ALUMINUM- AND FLUORIDE-INDUCED BEHAVIORAL ALTERATIONS THROUGH RESVERATROL IN RATS
}

\section{CHANDRA SHAKAR REDDY NALLAGOUNI, NAGESHWAR MESRAM, PRATAP REDDY KARNATI*}

Department of Zoology, Neurobiology Lab, University College of Science, Osmania University, Hyderabad, Telangana, India. Email: pratapkreddyou@gmail.com

Received: 26 July 2017, Revised and Accepted: 16 October 2017

\section{ABSTRACT}

Objective: The objective of the study was to investigate the ameliorative effects of resveratrol against aluminum- and fluoride-altered neurobehavioral activities.

Methods: Aluminum chloride (100 mg/kg body weight [bw])+sodium fluoride (10 mg/kg bw), aluminum chloride (100 mg/kg bw) + sodium fluoride $(10 \mathrm{mg} / \mathrm{kg} \mathrm{bw})+$ resveratrol (30 mg/kg bw), and resveratrol (30 mg/kg bw) alone were given orally to II, III, and IV groups, respectively, and Group-I was served as control for 8 weeks. The bw, brain weight, grip strength, learning ability, and behavioral activities were assayed.

Results: The results showed significantly $\left({ }^{*} \mathrm{p}<0.05\right)$ altered body and brain weights, learning ability, grip strength, and behavioral activities in GroupII, whereas significant $(* \mathrm{p}<0.05)$ reversal was observed in Group-III.

Conclusion: Taken together, the above findings conclude that resveratrol ameliorated aluminum and fluoride-altered neurobehavioral activities.

Keywords: Aluminum, Fluoride, Resveratrol, Weight, Behavior.

(C) 2018 The Authors. Published by Innovare Academic Sciences Pvt Ltd. This is an open access article under the CC BY license (http://creativecommons. org/licenses/by/4. 0/) DOI: http://dx.doi.org/10.22159/ajpcr.2018.v11i1.21620

\section{INTRODUCTION}

Aluminum and fluoride are widely used in many industrial fields due to their commercial value. There is conclusive evidence that aluminum compounds can reach systemic circulation through several routes, i.e., intraperitoneal [1], intramuscular [2], and ingestion [3,4] and accumulates in the body. Excessive accumulation of aluminum documented in the olfactory bulb, hippocampus, white matter, and cortex [5]. Aluminum in the presence of fluoride may potentiate oxidative and inflammatory stress, leading to altered neurobehavioral functions. Although neurotoxic mechanisms of aluminum and fluoride become clearer, more complete possible protectants against them can be anticipated, which promises better outcome in neurobehavioral disorders.

Resveratrol (3, 5, 4-trihydroxystilbene) is a naturally occurring polyphenol compound (phytoalexin family) found in grapes, nuts, various berries, grape wines, pines, legumes as well as in the roots of Japanese knotweed/Itadori plant, and produced in response to injury or when the plant is under attack by pathogens such as bacteria or fungi $[6,7]$. The intense interest in the use of resveratrol is due to its pleiotropic action as a molecule that affords protection against oxidative stress, inflammation, diabetes, obesity, cognitive dysfunction, and as a caloric restriction mimetic [8-11]. Hence, it is received notable interest in the scientific and medical community as possible treatment to combat several human chronic diseases [8]. Over the past three decades, studies have reported the health benefits of resveratrol and other stilbenes. These beneficial health effects include life-span extension, weight loss, protection against cardiovascular diseases, neurodegenerative diseases, stroke-induce brain damage, cancer, and cancer metastasis [12,13]. These investigations led us to look into the protective effects of resveratrol against aluminum- and fluoride-induced neurodegeneration in rats. Recent past, we have published protective effects of resveratrol against aluminum- and fluoride-induced oxidative stress [14], and there are no reports on protective effects of resveratrol against aluminum along with fluorideinduced neurobehavioral disorders. Thus, the purpose of the present investigation was to examine the protective efficacy of resveratrol on learning ability, behavioral activities, and grip strength following $\mathrm{Al}$ and $\mathrm{F}$ exposure. In practical terms, a critical analysis of this report on the resveratrol effects on aluminum and fluoride intoxication can be of great benefit to ameliorate the neurobehavioral disorders.

\section{METHODS}

\section{Chemicals}

Resveratrol, aluminum chloride, and sodium fluoride were purchased from Sigma Aldrich Company. All other chemicals used in the investigation were of analytical grade.

Healthy SD rats were procured from the National Institute of Nutrition, Hyderabad, Telangana, India. The animals were 6 weeks old, and their body weight (bw) was in the range of $180 \pm 10 \mathrm{~g}$.

All experiments were performed in accordance with ethical guidelines (CPCSEA No: 383/01/a/CPCSEA). The rats were housed in cages at hygienic conditions and maintained room temperature at $25-27^{\circ} \mathrm{C}$ with $12 \mathrm{~h}$ light/dark cycle for a week before the experimentation to acclimatize to the laboratory conditions. They were provided with water ad libitium and standard rat chow procured from the National Institute of Nutrition, Hyderabad, Telangana, India. The animals were alienated into 4 groups of 5 animals each. Control group (Group-1) was given free access to diet and water. Experimental groups, i.e., Group-II $\left(\mathrm{AlCl}_{3}+\mathrm{NaF}\right)$ received a dosage of $100 \mathrm{mg} / \mathrm{kg}$ bw of aluminum chloride and $10 \mathrm{mg} / \mathrm{kg}$ bw of sodium fluoride, Group III $\left(\mathrm{AlCl}_{3}+\mathrm{NaF}+\mathrm{Res}\right)$ received a dosage of $100 \mathrm{mg} / \mathrm{kg}$ bw of aluminum chloride $+10 \mathrm{mg} / \mathrm{kg}$ bw of sodium fluoride and $30 \mathrm{mg} / \mathrm{kg}$ bw of resveratrol, and Group IV (Res) received resveratrol alone with a dosage of $30 \mathrm{mg} / \mathrm{kg}$ bw. All the treatments were given orally with the orogastric tube. The doses were administered between 08:00 and 09:00 h daily for 8 weeks. 


\section{Physical parameters}

\section{Body and brain weight}

The bw changes of all groups were carefully recorded throughout the study. The animals were weighed using the standard weighing machine at the beginning of the experiment, and finally before sacrificing for the experimentation and the brains of four animal groups were weighed immediately after removal of them for further studies. The results were noted and analyzed.

\section{Behavioral parameters}

All behavioral tests were performed after acclimatization, adaptation (2-3 days) of animals before the experiment.

\section{Rotarod test}

The time of the instrument adjusted to $0 \mathrm{~s}$ and the rotational speed to $20 \mathrm{rpm}$ before the experimentation. Animals of all groups were kept on a rotating rod and pressed the start button. Animals were them self-coordinated the body on rotating rod (innate antagonistic reflex activity), but when they were unable to cope up, fallen on the base of instrument consisting a sensor, the stopwatch was stopped [15]. The time was noted, and the results were analyzed.

\section{Open field test}

The open field test is designed to measure behavioral activities such as locomotor activity, hyperactivity, and exploratory behaviors (emotional reactivity/anxiety). In this experiment, the open field behavior of rat was assayed in a wooden box measuring $90 \mathrm{~cm} \times 90 \mathrm{~cm} \times 30 \mathrm{~cm}$. The floor of the area was divided into 36 equal squares. The animals were allowed into open field for $5 \mathrm{~min}$. Each rat was placed in the corner of the field. The number of squares crossed with all paws (crossing), the standings on the hind legs (rearing), standing on hind legs and placing forelimbs on the wall of arena (wall rearing), placing the nose against wall or floor (sniffing), wiping, liking, combining, or scorching of any part of the body (grooming) were counted as the sum of all open-field tasks (total behavior) [16], and the obtained results were analyzed.

\section{Maze learning test}

A maze is a puzzle in the form of a complex branching passage through which the solver (animal) must find a route. Maze learning is the process of learning a route (typically by rats or mice) through a maze to obtain reinforcement. This process is a popular experiment in behavioral laboratory and is the main method of studying spatial learning. Before starting the experiment, the animals were kept fasting for $12 \mathrm{~h}$ and used for maze learning experimentation. The animals were allowed into maze learning board and noted the goal (food) reached time [17]. The results were analyzed.

\section{Statistical analysis}

The results tested for significance using one-way analysis of variance (ANOVA). Post hoc tests also performed at $5 \%$ level of significance and are depicted in the form of bar charts, which are equivalently represents the data of mean \pm standard error of the mean.

\section{RESULTS}

\section{Physical parameters}

\section{Body weight}

The bw was significantly $\left({ }^{*} \mathrm{p}<0.05\right)$ decreased $(10.45 \%)$ in aluminum chloride + sodium fluoride-treated group as compared to the control group, whereas the bw was significantly $\left({ }^{*} \mathrm{p}<0.05\right)$ reversed $(8.73 \%)$ in the group treated with resveratrol along with aluminum chloride+sodium fluoride treatment. The resveratrol alone administered group showed insignificant change as compared to the control group (Fig. 1).

\section{Brain weight}

The brain weight was significantly $\left({ }^{*} \mathrm{p}<0.05\right)$ decreased $(32.09 \%)$ in aluminum chloride + sodium fluoride-treated group as compared to the control group, whereas the brain weight was significantly $\left({ }^{*} \mathrm{p}<0.05\right)$ reversed $(22.22 \%)$ in the group treated with resveratrol along with aluminum chloride+sodium fluoride treatment. The group administered with resveratrol alone showed the insignificant difference as compared to the control group (Fig. 2).

\section{Behavioral tests}

Rotarod test

The control group rats were showed normal locomotor activities. Aluminum chloride + sodium fluoride-treated group showed significantly $\quad\left({ }^{*} \mathrm{p}<0.05\right)$ decreased $\quad(59.09 \%)$ locomotor activity when compared to control group animal's activity. The resveratrol administered along with aluminum chloride+sodium fluoride group showed significantly $\left({ }^{*} \mathrm{p}<0.05\right) \quad$ improved $(35.53 \%)$ locomotor activity, and the values obtained were closer to the control group. The resveratrol alone treated group showed insignificant alterations as compared to the control group (Fig. 3).

\section{Maze learning test}

The control group rats were showed normal learning activity in exposure duration, but the aluminum chloride + sodium fluoride-treated group

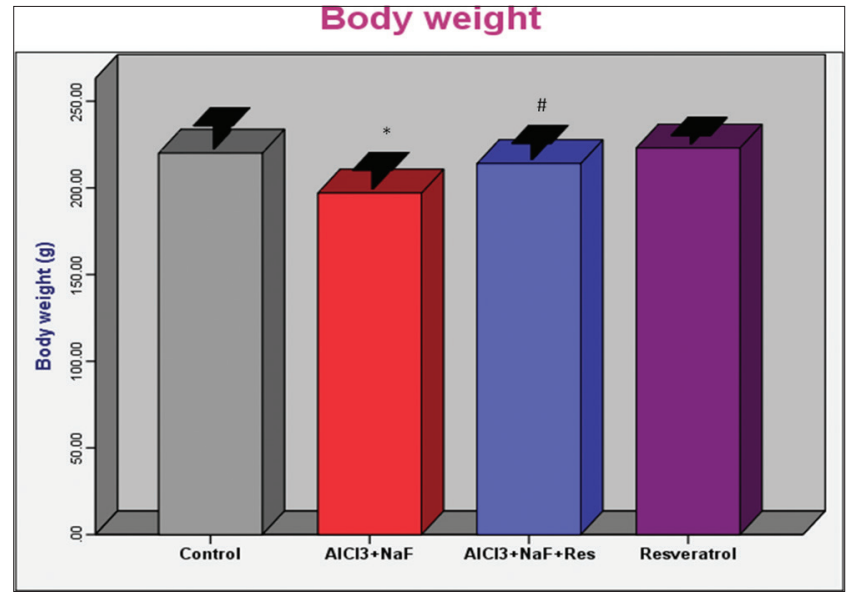

Fig. 1: Effect of resveratrol treatment on body weight (bw) in rats subjected to aluminum chloride along with sodium fluoride treatment. The bw is expressed in grams $(\mathrm{g}){ }^{*} \mathrm{p}<0.05$ as compared to control group and ${ }^{\#} \mathrm{p}<0.05$ as compared to $\mathrm{AlCl}_{3}-$ and NaF-treated group. Each value is mean \pm standard error

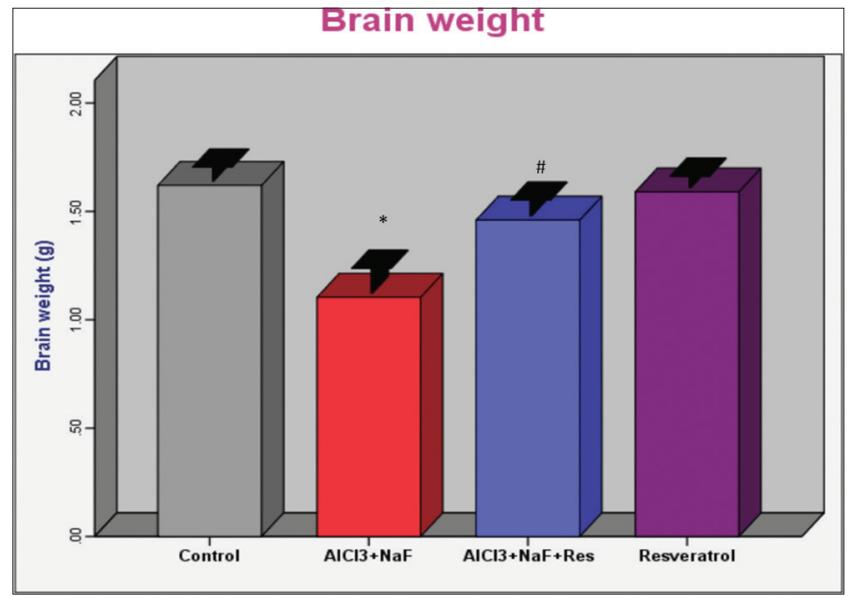

Fig. 2: Effect of resveratrol treatment on brain weight in rats subjected to aluminum chloride along with sodium fluoride treatment. Brain weight is expressed in grams $(\mathrm{g}){ }^{*} \mathrm{p}<0.05$ as compared to control group and $" \mathrm{p}<0.05$ as compared to $\mathrm{AlCl}_{3}$ - and

NaF-treated group. Each value is mean \pm standard error 
showed significantly $\left({ }^{*} \mathrm{p}<0.05\right)$ decreased $(131.71 \%)$ learning, memory, and cognition activities. The resveratrol along with aluminum chloride + sodium fluoride-administered group showed significant $\left({ }^{*} \mathrm{p}<0.05\right)$ improvement $(87.71 \%)$ in the behavioral activities. The resveratrol alone administered group showed insignificant change as compared to the control group (Fig. 4).

\section{Open field test}

The control group rats showed normal activities, while the experimental (aluminum chloride + sodium fluoride treated) animal group showed significantly $\left({ }^{*} p<0.05\right)$ decreased $(34.50 \%)$ emotional and normal activities, whereas resveratrol along with aluminum chloride + sodium fluoride-administered group showed significantly $\left({ }^{*} \mathrm{p}<0.05\right)$ improved (13.16\%) behavioral activities. The group administered with resveratrol alone showed insignificant alterations as compared to the control group (Fig. 5).

\section{DISCUSSION}

Monitoring of the bw provides the preliminary information of the study and account on this, and researchers further evaluate the toxic manifestations and protective functions of different agents which they want to investigate for the scientific betterment. In the present study, a marked decrease in bw and brain weight in aluminum and fluoride exposed animals was observed as compared to the control group animals. These findings are also in line with the previous studies done in other laboratories [18-20], and these changes were significantly reversed when resveratrol administered concomitantly with aluminum and fluoride. On the other hand, resveratrol alone given animal's body and brain weights were very nearer to the control group animal's weight. This shows that resveratrol has significant protective effect against aluminum and fluoride and has not shown any kind of toxic effect as compared to the control group.

The importance of neurobehavioral studies in risk assessment lies in the fact that behavior can be regarded as the net output of the sensory, motor, and cognitive functions occurring in the nervous system and can serve as potentially sensitive endpoints of chemically induced neurotoxicity [21]. Brain tissues, especially hippocampus, are the major mediators of spatial learning and memory and have previously been shown to be impaired in aging subjects experiencing cognitive declines [22]

$\mathrm{Al}$ as an important neurotoxin has been investigated extensively both in vitro and in vivo and is associated with cognitive dysfunction and various mental diseases. Neuropathological, biochemical, and epidemiological studies suggest that $\mathrm{Al}$ contributes to the progression of several neurodegenerative diseases, including Alzheimer's disease and Parkinson's disease $[23,24]$. It is also showed that the SLM function was significantly impaired and significant karyopyknosis of hippocampal neurons. This phenomenon could be attributed to the ability of aluminum to interfere with downstream effector molecules, such as cyclic GMP, involved in long-term potentiation [25]. This disruption could then explain the memory impairment and neurobehavioral deficits observed. In the present study, the results showed that the spatial learning and memory (SLM) function was significantly impaired in the aluminum- and fluoride-intoxicated group as compared with the control group. This result is in accordance with the previous studies [26-30], whereas the SLM function was significantly reversed in the resveratrol treated against aluminum along with fluoride-treated group as compared to the aluminum along with fluoride-treated group, showing the protective effect of resveratrol. This observation is in agreement with the earlier findings showing protection of resveratrol against neurodegeneration and preserves cognitive function [31-33]. Resveratrol alone treated group did not show any changes as compared to the control group.

The open field test is a classic behavioral experiment to assess an anxiety state and exploratory behavior of the animals in a novel environment. Rotarod is the test designed to assess the motor

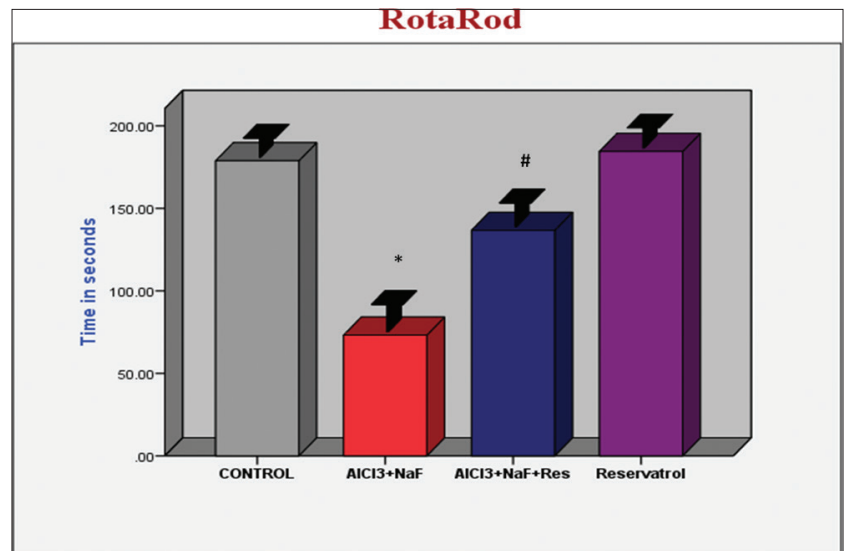

Fig. 3: Effect of resveratrol treatment on locomotor activity in rats subjected to aluminum chloride along with sodium fluoride treatment. Locomotor activity is expressed in seconds. ${ }^{*} \mathrm{p}<0.05$ as compared to control group and ${ }^{\#} \mathbf{p}<0.05$ as compared to $\mathrm{AlCl}_{3}$ - and

$\mathrm{NaF}$-treated group. Each value is mean \pm standard error

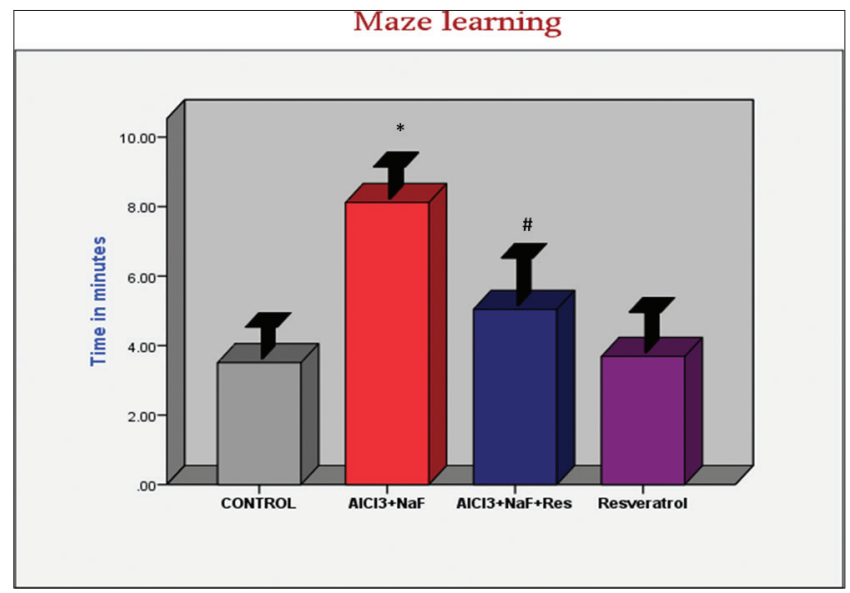

Fig. 4: Effect of resveratrol treatment on learning in rats subjected to aluminum chloride along with sodium fluoride treatment. Maze learning latency time is expressed in minutes. ${ }^{*} \mathbf{p}<0.05$ as compared to control group and $\# p<0.05$ as compared to $\mathrm{AlCl}_{3}$ - and $\mathrm{NaF}$-treated group. Each value is mean \pm standard error

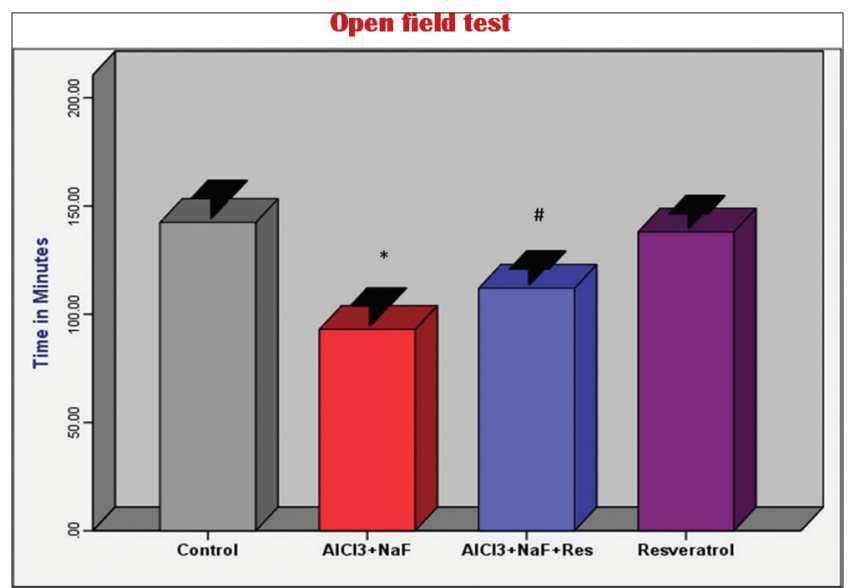

Fig. 5: Effect of resveratrol treatment on behavioral activity in rats subjected to aluminum chloride along with sodium fluoride treatment. Behavioral activity is expressed in minutes. ${ }^{*} \mathbf{p}<0.05$ as compared to control group and $\# \mathbf{p}<0.05$ as compared to $\mathrm{AlCl}_{3}$ - and NaF-treated group. Each value is mean \pm standard erro 
coordination activity. Behavioral changes as indicators of neurotoxicity may be more sensitive than neurochemical alterations, and these changes may be observed during $\mathrm{Al}$ and $\mathrm{F}$ exposure. The present study reports that aluminum and fluoride intoxication induced a significant reduction in locomotor activity of rats as well as grip strength. These results are in accordance with the results reported in Sprague-Dawley rats using the same test [34], the diminished motor activities and grip strength reported after Al exposure in mice [35], and also with decreased total level of locomotor activity after $\mathrm{Al}$ treatment in adult mice Swiss-Webster [36]. These findings are also in line with the previous studies [37-40]. Therefore, high levels of $\mathrm{Al}$ and $\mathrm{F}$ not only interfere with the memory but also affect the motor functions and lead to decreased motor activities. Furthermore, the locomotor activity and grip strengths are nearer to control group in resveratrol administered against aluminum- and fluoride-intoxicated group. The obtained result is in accordance with the earlier reports suggesting that resveratrol showed significant improvement in spatial memory through the reduction in lipid peroxidation and iNOS levels and increased production of the enzyme hemeoxygenase 1 [41]. The replenished grip strength is in accordance with the earlier findings showing that resveratrol administration was shown to protect mice from MPTP-induced motor coordination impairment [42]. This shows that resveratrol is potent in the amelioration of Al- and F-induced toxicity. On the other hand, resveratrol alone given animals locomotor activity and grip strengths were very nearer to the control group animals. This indicates that resveratrol has significant protective effects against aluminum and fluoride intoxication and it did not show any kind of toxic effect.

Thus, the behavioral activities such as the general innate reflex motor coordination activity, emotional activity, cognitive behavior, anxiety state and exploratory behavior, grip strength, and learning ability were significantly decreased in aluminum chloride + sodium fluoridetreated group as compared to the control group of animals. This may be possible by the aluminum- and fluoride-induced oxidative stress initiated inflammation and injury produced metabolic deficits, excitotoxicity induced synaptic damage, neural network failure, microglia activation leading to apoptosis, necrosis of neural cell as well as neurochemical alterations leading to the pathological changes such as behavioral alterations in aluminum + fluoride-treated group and the above all pathological changes in behavioral activity were significantly reversed when resveratrol administered along with aluminum + fluoride. Furthermore, resveratrol alone treated group showed insignificant behavioral changes as compared to the control group.

\section{CONCLUSION}

This study reports the changes in the behavioral activities due to the aluminum along with fluoride intoxication. These changes were ameliorated by administration of resveratrol, playing a vital role in providing protection from neuronal damage. Thus, resveratrol is reported to be a persuasive neuroprotectant in preventing aluminum- and fluoride-induced alterations in behavioral activities.

\section{CONFLICTS OF INTEREST}

Declared none

\section{AUTHORS CONTRIBUTION}

Correspondence author contributed valuable guidance in completing the work, the first author did whole the work and second author assisted in animal handling and experimentation.

\section{ACKNOWLEDGMENT}

The authors would like to thank UGC, New Delhi, for providing BSRRFSMS (F.4-1/2006(BSR)/7-143/2007(BSR)) fellowship to NCR and BSR (F-19-118/2014 (BSR)) onetime grant, partial funds under DSA II- SAP (5-26/2015/DSA/SRA II) to KPR.

\section{REFERENCES}

1. Flarend R, Bin T, Elmore D, Hem SL. A preliminary study of the dermal absorption of aluminium from antiperspirants using aluminium-26. Food Chem Toxicol 2001;39:163-8.

2. Flarend RE, Hem SL, White JL, Elmore D, Suckow MA, Rudy AC, et al. In vivo absorption of aluminium-containing vaccine adjuvants using 26Al. Vaccine 1997;15:1314-7.

3. Walton J, Tuniz C, Fink D, Jacobsen G, Wilcox D. Uptake of trace amounts of aluminum into the brain from drinking water. Neurotoxicology 1995;16:187-90.

4. Yokel RA, Rhineheimer SS, Brauer RD, Sharma P, Elmore D, McNamara PJ. Aluminum bioavailability from drinking water is very low and is not appreciably influenced by stomach contents or water hardness. Toxicology 2001;161:93-101.

5. Zatta P, Favarato M, Nicolini M. Deposition of aluminum in brain tissues of rats exposed to inhalation of aluminum acetylacetonate. Neuroreport 1993;4:1119-22.

6. Langcake P, Pryce R. The production of resveratrol by Vitis vinifera and other members of the Vitaceae as a response to infection or injury. Physiol Plant Pathol 1976;9:77-6.

7. Soleas GJ, Dam J, Carey M, Goldberg DM. Towards the fingerprinting of wines: Cultivar-related patterns of polyphenolic constituents in Ontario wines. J Agric Food Chem 1997;45:3871-80.

8. Baur JA, Sinclair DA. Therapeutic potential of resveratrol: The in vivo evidence. Nat Rev Drug Discov 2006;5:493-506.

9. Cottart $\mathrm{CH}$, Nivet-Antoine V, Beaudeux JL. Review of recent data on the metabolism, biological effects, and toxicity of resveratrol in humans. Mol Nutr Food Res 2014;58:7-21.

10. Rai AR, Madhyastha S, Prabhu LV, Saralaya VV, Sahu SS, Rao G. Resveratrol reverses the restraint stress-induced cognitive dysfunction involving brain antioxidant system in rats. Int $\mathrm{J}$ Pharm Pharm Sci 2014;6:768-72.

11. Lalitha V, Korah MC, Sengottuvel S, Sivakumar T. Antidiabetic and antioxidant activity of resveratrol and vitamin-c Combination on streptozotocin induced diabetic rats. Int J Pharm Pharm Sci 2015;7:455-8.

12. McCormack D, McFadden D. A review of pterostilbene antioxidant activity and disease modification. Oxid Med Cell Longev 2013;2013:575482.

13. Kasiotis KM, Pratsinis H, Kletsas D, Haroutounian SA. Resveratrol and related stilbenes: Their anti-aging and anti-angiogenic properties. Food Chem Toxicol 2013;61:112-20.

14. Nalagoni CS, Karnati PR. Protective effect of resveratrol against neuronal damage through oxidative stress in cerebral hemisphere of aluminum and fluoride treated rats. Interdiscip Toxicol 2016;9:78-82.

15. Jones BJ, Roberts DJ. The quantiative measurement of motor incoordination in naive mice using an acelerating rotarod. J Pharm Pharmacol 1968;20:302-4.

16. Seibenhener ML, Wooten MC. Use of the Open Field Maze to measure locomotor and anxiety-like behavior in mice. J Vis Exp 2015;96:e52434.

17. Winocur G, Moscovitch M. Hippocampal and prefrontal cortex contributions to learning and memory: Analysis of lesion and aging effects on maze learning in rats. Behav Neurosci 1990;104:544-51.

18. Cherrot G, Desor D, Huntin MF, Burel D, Capoleghil B, Lehr PR. Effects of aluminum chloride on normal and uremic adult male rats: Tissue distribution, brain choline, acetyl transferase activity and some biological variable. Biol Trace Elem Res 1995;54:43-53.

19. Rani A, Neha, Sodhi RK, Kaur A. Protective effect of a calcium channel blocker "diltiazem" on aluminum chloride-induced dementia in mice. Naunyn Schmiedebergs Arch Pharmacol 2015;388:1151-61.

20. Sharma P, Ahmad SZ, Kumar A, Islam F, Mishra KP. Role of combined administration of iron and glutathione against aluminum induced oxidative stress in rat brain. J Trace Elem Med Biol 2007;21:63-70.

21. Evans HL. Markers of neurotoxicity: From behavior to autoantibodies against brain proteins. Clin Chem 1995;41:1874-81.

22. Vanguilder HD, Freeman WM. The hippocampal neuroproteome with aging and cognitive decline: Past progress and future directions. Front Aging Neurosci 2011;3:8.

23. Ferreira PC, Piai Kde A, Takayanagui AM, Segura-Muñoz SI. Aluminum as a risk factor for Alzheimer's disease. Rev Lat Am Enfermagem 2008;16:151-7.

24. Sánchez-Iglesias S, Méndez-Alvarez E, Iglesias-González J, MuñozPatiño A, Sánchez-Sellero I, Labandeira-García JL, et al. Brain oxidative stress and selective behaviour of aluminium in specific areas of rat brain: Potential effects in a 6-OHDA-induced model of Parkinson's disease. J Neurochem 2009;109:879-88. 
25. Bhalla P, Garg ML, Dhawan DK. Protective role of lithium during aluminium-induced neurotoxicity. Neurochem Int 2010;56:256-62.

26. Lu H, Hu J, Li J, Pang W, Hu Y, Yang H, et al. Optimal dose of zinc supplementation for preventing aluminum-induced neurotoxicity in rats. Neural Regen Res 2013;8:2754-62.

27. Yu L, Jiang R, Su Q, Yu H, Yang J. Hippocampal neuronal metal ion imbalance related oxidative stress in a rat model of chronic aluminum exposure and neuroprotection of meloxicam. Behav Brain Funct 2014;10:6

28. Walton JR. Cognitive deterioration and associated pathology induced by chronic low-level aluminum ingestion in a translational rat model provides an explanation of Alzheimer's disease, tests for susceptibility and avenues for treatment. Int J Alzheimers Dis 2012;2012:914947.

29. Zhang ZJ, Qian YH, Hu HT. The herbal medicine Dipsacus asper wall extract reduces the cognitive deficits and over expression of beta amyloid protein induced by aluminum exposure. Life Sci 2003;73:2443-54.

30. Canales JJ, Corbalán R, Montoliu C, Llansola M, Monfort P, Erceg S, et al. Aluminium impairs the glutamate-nitric oxide-cGMP pathway in cultured neurons and in rat brain in vivo: Molecular mechanisms and implications for neuropathology. J Inorg Biochem 2001;87:63-9.

31. Foti Cuzzola V, Ciurleo R, Giacoppo S, Marino S, Bramanti P. Role of resveratrol and its analogues in the treatment of neurodegenerative diseases: Focus on recent discoveries. CNS Neurol Disord Drug Targets 2011;10:849-62.

32. Novelle MG, Wahla D, Diéguez C, Bernier M, de Cabo R. Resveratrol supplementation: Where are we now and where should we go? Ageing Res Rev 2015;21:1-15.

33. Sun AY, Wang Q, Simonyi A, Sun GY. Resveratrol as a therapeutic agent for neurodegenerative diseases. Mol Neurobiol 2010;41:375-83.

34. Gonda Z, Lehotzky K, Miklósi A. Neurotoxicity induced by prenatal aluminum exposure in rats. Neurotoxicology 1996;17:459-69.

35. Hu H, Yang YJ, Li XP, Chen GH. Effect of aluminum chloride on motor activity and species-typical behaviors in mice. Zhonghua Lao Dong Wei Sheng Zhi Ye Bing Za Zhi 2005;23:132-5.

36. Golub MS, Donald JM, Gershwin ME, Keen CL. Effects of aluminum ingestion on spontaneous motor activity of mice. Neurotoxicol Teratol 1989;11:231-5

37. Abdel-Aal RA, Assi AA, Kostandy BB. Rivastigmine reverses aluminum-induced behavioral changes in rats. Eur $\mathrm{J}$ Pharmacol 2011;659:169-76.

38. Erazi H, Sansar W, Ahboucha S, Gamrani H. Aluminum affects glial system and behavior of rats. C R Biol 2010;333:23-7.

39. Liang RF, Li WQ, Wang H, Wang JX, Niu Q. Impact of sub-chronic aluminium-maltolate exposure on catabolism of amyloid precursor protein in rats. Biomed Environ Sci 2013;26:445-52.

40. Li N, Wang XY, Liu CC, Zhang QL, Niu Q. The effects of caspase-3 siRNA on the neurobehavior of mice exposed to aluminum. Zhonghua Lao Dong Wei Sheng Zhi Ye Bing Za Zhi 2011;29:343-8.

41. Huang TC, Lu KT, Wo YY, Wu YJ, Yang YL. Resveratrol protects rats from $\mathrm{A} ß$-induced neurotoxicity by the reduction of iNOS expression and lipid peroxidation. PLoS One 2011;6:e29102.

42. Lu KT, Ko MC, Chen BY, Huang JC, Hsieh CW, Lee MC, et al. Neuroprotective effects of resveratrol on MPTP-induced neuron loss mediated by free radical scavenging. J Agric Food Chem 2008;56:6910-3 